Experience of several types of continuing care services in the NHS has led us to believe that whenever development resources become available there are often more pressing demands than continuing care. Lest there be any doubt of the validity of this statement, we suggest that health authorities should apply the standards for accommodation which they impose on private nursing homes to their own continuing care wards.

In our health district the provision of private nursing home beds has accelerated to the point where over 40 beds are available per 1000 population over the age of 65 . At the same time the hospital bed pool for the elderly has dwindled, though its quality in terms of access to diagnostic facilities and input of rehabilitative skill has greatly improved. In such a district, where there is competition for patients by nursing homes with unhealthily large amounts of beds available, the question has to be posed, "Who should receive continuing care in the health service?" The answer is not dependent on physical disability but usually on the financial circumstances of individual patients and, in particular, their eligibility for supplementary benefit payment. The dual standards of care which can and do exist are unacceptable. Most patients are discharged to the care of their general practitioner in private nursing homes, a non-selective (by virtue of medical condition) few remain in hospital care.

Quality assurance for the individual patient can only be guaranteed by regular review and a sense of advocacy by the reviewer. It is quite clear that general practitioners do not have the time to visit their elderly patients in nursing homes and embark on multidisciplinary case conferences, whereas the tradition of geriatric medicine in Britain has established the multidisciplinary conference as the most meaningful way to review an individual's needs comprehensively. For some time in Weston super Mare specialist nurses have followed patient discharged from hospital into private nursing homes to confirm the suitability of the placement and, where necessary, to target paramedica resources so that the care, at least at the out set, has been appropriate for the needs of the patient. The private sector has been receptive to our continued involvement with patients, and some of the skills imparted by this "outreach" activity may have improved the overall standard of care within the private sector.

Major capital investment on chronic care within the health service is unlikely. What is urgently needed is a clear policy on the limits of the NHS' responsibility for providing a service for the elderly and disabled. The burning issue is whether or not the health service should be expected to provide long term inpatient care. Planning for the care of the elderly in particular is at a standstill in many health authorities through lack of clarity on this issue, and, by inference, the service provision to patients is variable and inconsistent between various areas of Britain.

C E BOWMAN Weston General Hospital, Weston super Mare, Avon BS23 4TQ

SIR,-Professor MacLennan reminds us that for many elderly chronically sick patients the reality of community care is quite simply a transfer from one sort of institution to another (12 March, p 732). He says that "proponents of the expansion in private institutional care emphasise that it takes pressure off a hard pressed health service." Such a view fails to take into account the impact which the concentration of large numbers of these highly dependen patients has on local general medical services, which in certain parts of Britain are being stretched o breaking point.

The General Medical Services Committee believes that the present arrangements for the planning and registration of nursing and residential homes are inadequate and fail to take account of the ability of local general practitioners to provide the services required. We have made it clear in our discussions with the Department of Health and Social Security and in our evidence to Sir Roy Griffiths's review of community care and the review of residential care by Lady Wagner that these patients have medical needs which are no different from those of patients in long stay hospitals. We have proposed that such homes should be required to appoint medical advisers and that such appointments should be a condition of registration. We have also recommended the establishment of a national inspectorate, similar to the health advisory service, to inspect and license nursing and residential homes, whether private, voluntary, or statutory.

In its white paper Promoting Better Health the government refers to the special needs of the elderly and to those doctors practising in areas where there is a growing number of nursing homes. Let us hope that this recognition leads to an improved and more appropriate service for these patients, who are among the most disadvantaged and deserving in our society.

General Medical Services Committee, British Medical Association London WC1H 9JP

J B LYNCH

SIR,-Professor W J MacLennan's leading article

(12 March, p 732) does much to put things into perspective in a subject which has been debated hotly for some years.

The article fails to highlight, however, the use of "contractual beds" in private nursing homes by local authorities. This has proved to be beneficial in alleviating the strain on hospital long stay systems as well as retaining the role of geriatricians in selecting the type of patient who would be admitted to such beds. Until quite recently this scheme has been operational in Brighton Health District and has contributed appreciably to "through put" in the local geriatric unit. (Alas, this too has fallen to the axe of cut backs.)

The current DHSS supplements which are available to patients with low incomes could be used more resourcefully if a tiered structure were introduced. This would take into account the geographical location of the nursing home. It is cheaper to set up a nursing home in the north and the DHSS supplements provided there should therefore reflect the lower weekly nursing hom rates that ought to be charged in these areas. "Means testing" of even the low income group and providing differential DHSS supplement rather than a "blanket" rate of $£ 170$ or whateve per week would be another example where costs could be cut. The extent of disability and the actua amount of nursing care required could form ye another basis where the tiered system would operate.

Prakash Ariya-Nayagam

Department of Medicine for the Elderly,

Brighton General Hospital

Brighton BN2 3EW

SIR,-Professor W J MacLennan interpreted Day's and Klein's excellent review of institutional care of the elderly ${ }^{1}$ as being particularly concerned about the difficulty of ensuring standards of care in the flourishing private nursing home sector. Our interpretation was that they emphasised that the problem of ensuring standards of care applied equally to other sectors providing institutional care for the elderly. We agree with the opinion expressed in both articles that there is a need to shif attention from the regulation of structure and process of care towards outcome in terms of quality of life.

Unfortunately, many pay lip service to quality of life but make little attempt objectively to measure quality of life. An instrument for measuring the quality of life of old people in residential care is available. ${ }^{2}$ We have developed this instrument for use in continuing hospital care and nursing homes, allowing comparisons to be made between these sectors. Quality of life outcomes include patient autonomy, choice, engagement, satisfaction with life, satisfaction with the home or ward, staff morale, staff $v$ patient oriented policy, homely environment, and patient characteristics (physical, cognitive, and behavioural dependency). We have found that the questionnaires have clarity and are well accepted by staff and patients and that good interobserver correlation is obtained for questionnaires with subjective components.

Professor MacLennan rightly draws attention to the need to improve regulation in the private nursing home sector, particularly in preadmission assessment. Nevertheless, valid measurement and comparison of quality of life outcomes in all sectors providing institutional care for the elderly are necessary to inform policy makers and prevent "emotional and political prejudice."

IAN PHILP W J MUTCH

Department of Medicine,

Ninewells Hospital and Medical School

Dundee DD1 9SY, Scotland

1 Day P, Klein R. Quality of institutional care and the elderly: policy issues and options. Br Med f 1987;294:384-7.

Peace SM, Hall JF, Hamblin GR. The quality of life of the elderly in residential care. London: Survey Research Unit, Polytechnic of North London: October 1979. (Research report No 1.)

\section{Treatment of prostatic cancer}

SIR,-Mr D A Gillatt and colleagues (27 February, p 644) favour the relative merits of surgical orchidectomy over medical orchidectomy even though they admit that most patients, given the choice, select medical orchidectomy. They further argue that the psychological effects of both procedures have not been studied. We conducted a randomised clinical trial comparing medical and surgical orchidectomy in advanced prostatic cancer, ${ }^{12}$ during which we conducted a psychological study using a standard cross validated psychological questionnaire, which was administered before and after treatment at three monthly intervals. $^{34}$

Fifty five patients who could be evaluated were randomised to medical orchidectomy using decapeptyl and 49 to surgical orchidectomy. No psychological difference was noted before treatment between the groups for anxiety, depression, cheerfulness, fatigue, energy, anger, composure, or thoughtfulness. By six months the decapeptyl group showed less fatigue, anger, composure, depression, and anxiety and more cheerfulness and energy than the surgical orchidectomy group. These results did not reach statistical significance, but there was a clear trend in favour of medical orchidectomy. A larger group of patients may give a statistically significant result. Since all our patients were fully aware of their diagnosis the psychological impact of the cancer seemed to override the immediate impact of surgical orchidectomy. When the patients were subsequently told about the clinical results of surgical and medical orchidectomy about $70 \%$ of those from the surgical group said that they would select 
medical orchidectomy given a choice; all the patients receiving decapeptyl preferred to continue receiving it as long as they were in remission.

As far as relative costs are concerned, all patients receiving decapeptyl can be treated from the time of diagnosis as outpatients, while most surgical patients are treated as inpatients using a genera anaesthetic. About $8-10 \%$ of these patients develop some minor complication, such as infection or wound breakdown, which delays their discharge thus using up valuable hospital beds. Further more, $20-30 \%$ of patients treated with surgica orchidectomy fail to respond to it and have therefore been subjected to an operation which is unnecessary, possibly psychologically damaging certainly not a universal choice of well informed patients, and expensive. Indeed, one can argue that all patients should be given long acting luteinising hormone releasing hormone analogues and only those patients who have a clinical response should be selected for surgical orchidec tomy, which works out cheaper the longer remis sion is maintained. Clearly, the costs of these long acting analogues will come down because of the competition that will result from the differen analogues soon to be available from different pharmaceutical companies.

The statement that surgical orchidectomy is cheaper is still debatable, and it is not possible to make a simple comparison of, say, 100 patients treated by either means since $20-30 \%$ of these patients will not receive the luteinising hormon releasing hormone analogue beyond three months, while surgical orchidectomy is not reversible.

H PARMAR

R H PHILLIPS

L EDWARDS

S E PARTRIDG

S L LIGHTMAN

\section{Departments of Oncology \\ Urology, and Medicine, \\ Westminster Hospital.}

London SW1 2AP

1 Parmar H, Phillips RH, Lightman SL, Edwards L, Allen L, Schally AV. Randomised controlled study of orchidectomy versus long-acting D-Trp-6-LHRH microcapsules in advanced prostatic cancer. Lancet 1985; ii: 1201-5.

2 Parmar H, Edwards L, Phillips RH, Allen L, Lightman SL. Orchidectomy versus D-Trp-6-LHRH in advanced prostatic cancer. Br 7 Urol 1987;59:248-54

3 Lorr M, Daston P, Smith IR. An analysis of mood states. Educational and Psychological Measurement 1967;27:89-96.

4 Johnson $M$, Hackman A. Cross validation and response sets in repeated use of mood questionnaires. British fournal of Social and Clinical Psychology 1977;16:235-9.

** This correspondence is now closed.-ED $B M 7$.

\section{The elderly in residential care}

SIR,-Miss Sue Lowrey and Dr Roger Briggs (20

February, p 541) refer to our study ${ }^{1}$ and state that

"specialist assessment by a geriatrician of elderly people applying for a move to residential care in Edinburgh results in only $7 \%$ of patients being placed in alternative accommodation." This statement, while correct, fails to convey the fuller meaning of our study and appears to reduce the value of preadmission assessment.

It is important to emphasise that $58 \%$ of patients referred were already known to our geriatric service; indeed, many of them were referred at our instigation in collaboration with the general practitioner. When these "known clients" are excluded from the calculation the figure of $7 \%$ roughly doubles.

In addition, $15 \%$ of our total, although judged fit for residential care, received further assessment (and treatment if necessary). Thus although they all went eventually into care, we hope they did so in a rather better state of health.

We have carried out this form of assessment for many years and still believe that it is valuable in safeguarding a scarce resource by ensuring that only those who need residential care will receive it. The same argument should apply to those who have been referred for private care. Surely decision to sentence an elderly person to lifelong institutional care (however well provided) is one which should be reached only after full multidisciplinary assessment of need.

ROGER G SMITH

Department of Geriatric Medicine,

J WILLIAMSON

City Hospital,

Edinburgh EH10 5BB

1 Rafferty J, Smith RG, Williamson J. Medical assessment of elderly persons prior to a move to residential care: a review of seven years' experience in Edinburgh. Age Ageing 1987; of seven 16 : $10-12$.

\section{Late abortions and the law}

SIR,-Dr Tony Smith fails to answer criticism made of his editorial by Dr D A McHardy and others (5 March, p 715). In his leading article Dr Smith stated with regard to postcoital contraception, "no doctor should be able to arrogate to himself the freedom to refuse on grounds of conscience to prescribe it." An individual docto must be allowed the freedom not to prescribe any treatment to which he objects on conscientious grounds. There is clearly an obligation on such a doctor that he should inform his patients that alternative opinions exist and almost certainly he should help her in obtaining such an opinion. If such an approach is adopted moralistic argument will not override the patient's right to be given an accepted treatment, and the freedom of the individual doctor to exercise his own conscience will be maintained.

Royal Free Hospital

PATRICK WALKer (

\section{Who needs pulse oximetry?}

SIR,-Dr John Zorab (5 March, p 658) ignores a range of uses of pulse oximetry by physiologists (who developed the technique) and respiratory physicians (who helped to bring it into clinical use). It is contributing steadily to our understanding of exercise physiology and pathophysiology and the mechanisms and management of respiratory disturbances during sleep, and it can be immensely useful in the management of both acute and chronic hypoxaemia. Finally, it can be important in safety monitoring. It is not only anaesthetists who risk obstructing the airway: respirologists do it too (with bronchoscopes) and frequently have to add to the risk by pouring saline into the lung for bronchoalveolar lavage.

W A SEED

Department of Medicine,

Cross and Westminster Medical School,

London W6 8RR

SIR,-Dr John Zorab suggests (5 March, p 658) that priority should be given to the acquisition of pulse oximeters. While we agree that the technique is potentially useful in a number of situations, including intensive care, further work needs to be done before oximetry can be recommended for routine use.

There are several limitations to pulse oximetry. The accuracy of the instruments in reflecting true oxygen saturation remains suspect, and the physiological reasons for this have been discussed recently. ${ }^{1}$ Manufacturers generally state that accuracy in terms of correlation with arterial blood co-oximetry ( 1 standard deviation) is about $1 \cdot 5 \%$ over the range of saturation $90-100 \%$. We are at present performing a meta-analysis of published data which suggests that the limits of agreement between these values may be less good than previously assumed.

There are insufficient data to assess accuracy in the hypoxic range. Extrapolation from the higher range is unreliable as the mathematical relation between the true saturation and the light absorbance through blood and tissue is unknown. The findings of Severinghaus and Naifeh suggest that the identification of hypoxia may be poor in terms of both level of saturation displayed and response time. ${ }^{2}$ Pulse oximetry may therefore not be appropriate for assessing the degree of desaturation of babies with cyanotic congenital heart disease.

Movement artefact is a major problem when patients are not anaesthetised or paralysed, and this limits the use of pulse oximetry outside the intensive care environment. We have examined the incidence of such artefacts in four commercially available machines when monitoring oxygen saturation in healthy infants aged under 12 months. ${ }^{3}$ The frequency of artefacts and reliability of their identification were different with each machine, and no model consistently distinguished true dips in saturation from artefact. Pulse oximetry is therefore less suitable than might be expected for monitoring apnoeic episodes.

Until medical and nursing staff are familiar with the "normal range" of oxygen saturation it is important to avoid confusion with partial pressure of oxygen. A value of $60 \mathrm{~mm} \mathrm{Hg}$ for a neonate may be acceptable, whereas a saturation of $60 \%$ is not.

Provided these various drawbacks are well understood by the user pulse oximetry is a useful technique with many applications in addition to intensive care. At the very least it provides a trend and at best a reliable way of assessing oxygenation. We have shown the feasibility of rapid measurement of saturation in a children's clinic, ${ }^{4}$ and we are now evaluating the use of oximetry in the management of babies with bronchopulmonary dysplasia receiving continuous low flow oxygen. Measurements over 24 hours are made on the general ward by nursing staff and at home by parents.

Improvements in technology are sure to lead to better performance. If accuracy can be assured and movement artefact minimised the technique should be valuable not only in the settings envisaged by Dr Zorab but also in a variety of other situations in paediatric practice.

G H LEAR

S LEVENE S A MCKENZIE

Rush Green Hospital

Romford, Essex RM7 0YA

1 Huch A, Huch R, König V, et al. Limitations of pulse oximetry. Lancet $1988 ; \mathrm{i}: 357-8$

2 Severinghaus JW, Naifeh KH. Accuracy of response of six pulse oximeters to profound hypoxia. Anaesthesiology 1987;67:551-8. 3 Levene S, Lear GH, McKenzie SA. Pulse oximetry in healthy sleeping infants; movement artefact and ease of use [Abstract]. Pediatric Reviews and Communications (in press)

4 Levene S. Pulse oximetry in children. Lancet 1988;i:415.

\section{Transporting critically ill patients by} ambulance

SIR,-We agree with Dr Julian Bion that critically ill patients should not be transported until they are physiologically stable (27 February, p 645). We also agree that it is useful to monitor blood pressure during ambulance transfer of the critically ill. Monitoring of these patients is important to try to 